\title{
Controle da Artrite-Encefalite Caprina, em um capril comercial endemicamente contaminado
}

Anee Valéria Mendonça STACHISSINI José Rafael MODOLO Roberto Soares de CASTRO ${ }^{2}$ Barbára Lima Simioni LEITE ${ }^{1}$ João Pessoa ARAúJO JÚNIOR ${ }^{3}$

Carlos Roberto PADOVANI ${ }^{3}$

Correspondência para: JOSÉ RAFAELMODOLO Departamento de Higiene Veterinária e Saúde Pública

Faculdade de Medicina Veterinária e Zootecnia

Universidade Estadual Paulista

Caixa Postal 524

18618-000-Botucatu -SP

jrmodolo@fmvz.unesp.br

Recebido para publicação: 12/09/2005 Aprovado para publicação: 07/02/2007

\author{
1 - Departamento de Higiene Veterinária e Saúde Pública da Faculdade de \\ Medicina Veterinária e Zootecnia da Universidade Estadual Paulista, \\ Botucatu - SP \\ 2 - Departamento de Medicina Veterinária da Universidade Federal de \\ Pernambuco, Recife - PE \\ 3 - Instituto de Biociências da Universidade Estadual Paulista, Botucatu - SP
}

\section{Resumo}

Palavras-chave:

Caprino.

Lentivirus.

A CAE é provocada por um lentivírus. Os animais infectam-se, principalmente, quando mamam colostro e/ou leite contaminados. Neste trabalho, propôs-se um plano de controle da CAE, sem que se sacrificassem as mães contaminadas. Utilizaram-se 39 cabritas, nascidas de mães soropositivas para a CAE. Após o nascimento, as cabritas foram isoladas das mães e alimentadas com colostro de cabras soronegativas, tratado termicamente, e com leite de cabra pasteurizado, até os dois meses. Submeteram-se todas as cabritas ao teste sorológico, trimestralmente, do nascimento aos 12 meses; segregaram-se as soropositivas do rebanho. O grupo controle consistiu de 12 cabritos, nascidos de cabras soropositivas, os quais permaneceram com suas mães. O procedimento de diagnóstico foi o mesmo, mas não foram segregados os positivos. Ao final de 12 meses, 34 (87\%) animais do grupo experimental permaneceram soronegativos, com limites de confiança de $76 \%$ a $98 \%$; nos animais do grupo controle, a taxa de negatividade acumulada foi de $17 \%$, com limites de confiança entre $0 \%$ e $38 \%$. Com esses resultados, conclui-se que o plano proposto é viável para garantir o controle da enfermidade, em rebanhos contaminados, ou seja, a não-adoção do mesmo pode levar à contaminação dos animais nascidos de cabras infectadas.

\section{Introdução}

A artrite-encefalite caprina (CAE) é uma síndrome multissistêmica, provocada por um lentivírus, e caracteriza-se por provocar artrite, mamite e pneumonia, em animais adultos, e leucoencefalomielite, em jovens $\mathrm{s}^{1,2,3}$.

Possui ampla distribuição mundial e gera grandes perdas econômicas devido à baixa produção de leite e descarte de animais, com renovação forçada dos rebanhos e baixo aproveitamento do potencial genético dos caprinos infectados ${ }^{4}$.

Os animais infectam-se, principalmente, quando mamam o colostro e/ou leite contaminados, ou pelo contato próximo e prolongado com animais portadores do vírus $^{3}$. A transmissão intra-uterina do vírus da artrite-encefalite caprina (CAEV) ainda não foi demonstrada; no entanto, cabritos nascidos de mães contaminadas têm até 15\% de soroconversão inexplicada, aos seis meses de idade, a despeito de terem sido alimentados com leite pasteurizado ${ }^{5,6}$.

O diagnóstico da CAE pode ser confirmado pela pesquisa de anticorpos específicos para esses lentivírus ${ }^{7}$, sendo o teste sorológico de imunodifusão em gel de ágar (IDGA) o mais difundido.

Não há vacina ou tratamento eficaz para qualquer forma da doença, sendo necessária a profilaxia de planejamento para a saúde do rebanho ${ }^{8,9}$ que, de maneira geral, se baseia em testes sorológicos sensíveis e específicos, aliados a medidas de controle, 
Tabela 1 - Limites de confiança da taxa de negatividade acumulada pelo teste de IDGA, segundo o momento de avaliação

\begin{tabular}{|c|c|c|c|c|}
\hline Período & Grupo* & $\begin{array}{c}\text { Taxa de } \\
\text { negatividade (\%) }\end{array}$ & $\begin{array}{c}\text { Limite inferior } \\
(\%)\end{array}$ & Limite superior (\%) \\
\hline \multirow{2}{*}{ Nascimento } & Controle & 100 & 100 & 100 \\
\hline & Experimental & 100 & 100 & 100 \\
\hline \multirow{2}{*}{3 meses } & Controle & 100 & 100 & 100 \\
\hline & Experimental & 95 & 88 & 100 \\
\hline \multirow{2}{*}{6 meses } & Controle & 75 & 50 & 100 \\
\hline & Experimental & 92 & 84 & 100 \\
\hline \multirow{2}{*}{9 meses } & Controle & 33 & 7 & 59 \\
\hline & Experimental & 90 & 81 & 99 \\
\hline \multirow{2}{*}{12 meses } & Controle & 17 & 0 & 38 \\
\hline & Experimental & 87 & 76 & 98 \\
\hline
\end{tabular}

* Experimental $(\mathrm{n}=39) *$ Controle $(\mathrm{n}=12)$

principalmente no que se refere ao fornecimento de colostro e leite aos animais jovens ${ }^{10}$.

Técnicas para salvar a progênie e conservar o potencial genético de cabras infectadas, sem sacrificá-las, como primeira instância, oferecem vantagens, com a formação de rebanhos não infectados a partir de rebanhos endemicamente infectados ${ }^{11}$.

Nesse sentido, este trabalho teve como objetivo propor um plano de controle da CAE, em um rebanho comercial endêmica e naturalmente infectado, sem se sacrificarem as cabras contaminadas.

\section{Materiais e Métodos}

Para o grupo experimental, foram utilizadas 39 cabritas, nascidas de cabras leiteiras, sorologicamente positivas para a CAE e diagnosticadas pela IDGA. Os animais foram mantidos sob regime de confinamento, em um capril comercial. Imediatamente após o nascimento, as cabritas foram isoladas de suas mães e alimentadas, nas primeiras 36 horas de vida, com colostro de cabras soronegativas para a CAE, tratado termicamente a $56^{\circ} \mathrm{C}$, por 60 minutos, e com leite de cabra pasteurizado, até os dois meses de vida. Todas as cabritas foram submetidas ao teste de IDGA, trimestralmente, do nascimento (antes do oferecimento do colostro) até os 12 meses; segregaram-se os animais soropositivos do rebanho. A técnica de IDGA foi realizada de acordo com Cutlip, Jackson e Laird ${ }^{12}$, utilizando-se antígeno preparado pela concentração por diálise de sobrenadantes de células de membrana sinovial caprina, infectadas com a amostra CAEV Cork, de acordo com a descrição de Castro et al. ${ }^{13}$.

O grupo controle consistiu de 12 cabritos, de ambos os sexos, também nascidos de cabras soropositivas para CAE, pelo teste de IDGA, os quais permaneceram com suas mães e foram submetidos ao mesmo procedimento de diagnóstico, não sendo, no entanto, segregados os positivos.

$O$ estudo da taxa de negatividade acumulada, nos dois grupos avaliados, foi realizado em diferentes momentos, utilizandose os limites de confiança $(95 \%)$ para a proporção de ocorrência. ${ }^{14}$

\section{Resultados e Discussão}

A tabela 1 apresenta os limites de confiança da taxa de negatividade acumulada, pelo teste de IDGA, segundo o momento de avaliação.

Ao final de 12 meses, 34 (87\%) animais do grupo experimental permaneceram soronegativos ao teste de IDGA, com limites 
de confiança de $76 \%$ a $98 \%$ (Tabela 1). Resultados semelhantes também foram encontrados por Mackenzie et al. ${ }^{11}$ e East et al. ${ }^{6}$, que obtiveram, respectivamente, $90 \%$ e $85 \%$ de soronegatividade. Vale ressaltar, entretanto, que o primeiro autor utilizou 10 animais, em 12 meses de estudo; o segundo, 40 caprinos, durante cinco meses. Comparando-se os resultados deste experimento a estudos semelhantes de Rowe et al. ${ }^{15}$, a taxa de negatividade $(87 \%)$ foi consideravelmente superior à encontrada pelos pesquisadores $(76,8 \%)$.

Quanto aos caprinos do grupo controle, a taxa de negatividade acumulada foi de $17 \%$, com limites de confiança entre 0\% e 38\% (Tabela 1), ou seja, apenas dois animais permaneceram soronegativos, diferindo dos resultados de Mackenzie ${ }^{11}$, que não obteve negatividade. Achados semelhantes aos da presente pesquisa foram obtidos por Rowe et al. ${ }^{15}$ e por East et al. ${ }^{6}$ Os primeiros mostraram que $61,6 \%$ a $85,0 \%$ das soroconversões dos cabritos de seu experimento ocorreram quando utilizaram leite de cabra não pasteurizado, reduzindo a taxa de soroconversão em 2,5 a 6,7 vezes quando a alimentação foi feita com leite caprino pasteurizado. East et al. ${ }^{6}$, por sua vez, relataram que, em $80 \%$ a $100 \%$ das vezes, a ingestão repetida de leite infectado com CAEV leva à infecção.

Com esses resultados, pode-se concluir que o plano proposto é viável para garantir o controle da enfermidade, em rebanhos endemicamente contaminados, ou seja, a não-adoção do mesmo poderá levar à infecção dos caprinos nascidos de cabras infectadas, mantendo-se, portanto, um "círculo vicioso" da infecção, permanecendo a endemicidade da doença.

No entanto, apesar da comprovada diminuição da prevalência do CAEV nos rebanhos caprinos em que se adotam eficientes programas de controle, citados por mais autores neste trabalho, a soroconversão de alguns animais pode continuar ocorrendo ao longo de suas vidas. No presente estudo, por exemplo, cinco animais (13\%) apresentaram resultados positivos para o CAEV, pelo teste de IDGA, entre três e 12 meses de idade, índice semelhante aos relatados por Mackenzie et al. ${ }^{11}$, Rowe et al. ${ }^{5}$ e East et al. ${ }^{6}$

Essas ocorrências são motivos de preocupação epidemiológica, pois a condição de negatividade no rebanho requer que todos os animais sejam, sempre que testados, negativos ao CAEV.

Não obstante o descrito acima, nessas circunstâncias, a base a ser adotada deverá ser a vigilância sanitária permanente, na propriedade, o que poderá proporcionar condições para a erradicação da doença, ou a obtenção de uma taxa de infecção que permita a manutenção das matrizes infectadas, mas com crias sadias.

É importante enfatizar que, além das condições de manejo dos caprinos, o grau de conscientização dos criadores e o tipo de assistência aos animais poderão ser fatores limitantes, influenciando diretamente no êxito do planejamento de saúde proposto ${ }^{16}$.

\section{Caprine Arthritis-Encephalitis control in an endemically contaminated commercial goat farm}

\section{Abstract}

CAE is caused by a lentivirus. The animals are mainly infected when taking contaminated colostrums and/or milk. This study proposed a CAE control strategy without sacrificing contaminated mothers. Thirty-nine female kids, born to CAE seropositive mothers were isolated from their mothers at birth and fed heat-treated colostrum and pasteurized milk from seronegative goats up to two months of age. All kids were submitted to three-monthly serological tests from birth to 12 months; seropositives were segregated from the herd.
Key-words:

Caprine.

Lentiviruses.

Caprine arthritisencephalitis.

Control. 
The control group consisted of 12 kids born to seropositive mothers that remained with their mothers. Diagnosis was the same, but seropositve animals were not segregated. At the end of 12 months, $34(87 \%)$ animals from the experimental group remained seronegative with $76 \%$ to $98 \%$ confidence limits; in control group animals, the accumulated negativity rate was $17 \%$, with $0 \%$ and $38 \%$ confidence limits. These results show that the proposed plan is viable to assure disease control in contaminated herds and that without it contamination can pass to animals born to infected goats.

\section{Referências}

1 CORK, L. C. Differential diagnosis of viral leukoencephalomyelitis of goats. Journal of the American Veterinary Medical Association, v. 169, n. 12, p. 1303-1306, 1976

2 CRAWFORD, T. B. et al. Chronic arthritis in goats caused by a retrovirus. Science, v. 207, n. 4434, p. 997-999, 1980.

3 NARAYAN, O. Lentiviruses are etiological agents of chronics diseases in animals and acquired immunodeficiency syndrome in humans. Canadian Journal of Veterinary Research, v. 54, n. 1, p. 42-48, 1990.

4 FRANKE, C. R. Uma virose emergente ameaça o rebanho caprino nacional: artrite-encefalite caprina (CAE). Bahia Agrícola, v. 2, p. 24-27, 1998.

5 ROWE, J. D. et al. Risk factors associated with the incidence of seroconversion to caprine arthritisencephalitis virus in goats on California dairies. American Journal of Veterinary Research, v. 53, n. 12, p. 23962403, 1992.

6 EAST, N. E. et al. Modes of transmission of caprine arthritis-encephalitis virus infection. Small Ruminant Research, v. 10, n. 3, p. 251-262, 1993.

7 McGUIRE, T. C. et al. Caprine arthritis-encephalitis lentivirus transmission and disease. Current Topics in Microbiology Immunology, v. 160, p. 61-75, 1990.

8 GARCIA, M. Artrite-encefalite caprina: uma nova doença no Brasil. A Hora Veterinária, v. 76, p. 57-59, 1993.

9 PERETZ, G.; ASSO, J.; DEVILLECHAISE, P. Le CAEV: revue des connaissances actuelles et conséquences pratiques. Revue de Medecine Veterinaire, v. 144, p. 93-98, 1993.

10 PHELPS, S. L.; SMITH, M. C. Caprine arthritisencephalitis virus infection. Journal of the American Veterinary Medical Association, v. 203, n. 12, p. 16631666, 1993.

11 MacKENZIE, R. W. et al. A successful attempt to raise goat kids free of infection with caprine arthritis encephalitis virus in a endemically infected goat herd. New Zealand Veterinary Journal, v. 35, p. 184-186, 1987.
12. CUTLIP, R. C.; JACKSON, T. A.; LAIRD, O. A Immunodiffusion test for ovine progressive pneumonia. American Journal of Veterinary Research, v. 38, n. 7 p. 1081-1084, 1977.

13 CASTRO, R. S. et al. Isolamento e identificação pela imunofluorescência direta e reação em cadeia de polimerase do vírus da artrite-encefalite caprina. Arquivo Brasileiro de Medicina Veterinária e Zootecnia, v. 51 n. 3, p. 235-240, 1999.

14 STREINER, D. L.; NORMAN, G. R. The bare essentials. In: 1994. 260 p. Bioestatisti

15 ROWE, J. D. et al. Cohort study of natural transmission and two methods for control of caprine arthritis-encephalitis virus infection in goats on a California dairy. American Journal of Veterinary Research, v. 53, n. 12, p. 2386-2395, 1992a.

16 MODOLO, J. R. et al. Planejamento de saúde animal para o controle da artrite-encefalite caprina. Botucatu: Gráfica Santana, Cultura Acadêmica, 2003. 78 p. 